\title{
对一年来人工降水工作的一些体会
}

\author{
顧 震 潮 \\ （中国科学院地球物理研究所）
}

在去年串裂烈烈的大跃进中，气象工作也有許多 飞跃的成就，人工降水工作就是其中一个有代表性的 方面。

人工降水工作是在去年 8 月初首先在 吉 林 开始 的。当时只經过很短时閒的准备，在技术力量很少的 情况下就掎起来了。接着，在西北的䃼連山，在湖北、 河北、安徽等地也开始进行試驗。到去年年底，不仅 在上迅地区取得了地面操作和飞机操作的一些 結 果, 而且还有其他地区的地方气象工作人員，也在經过短 期学习后开始了人工降水工作。

今年以来，許多省依靠地方力量継續作了許多試 驗,同时还在几个地区重点地进行了人工降雨試驗。其 中，敨多試驗的成績是明显的，尽管所取得的科学数 据还不能完全合乎要求，但一般在工作中都已經明确 注意到积取科学数据的問題, 抹且装备起了一些可以 試用的仪器。气象工作者还参加了土法消管工作，亲 眼覌測了土炮的作用,看到了一些很有意思的現策,对 人工降雨工作很有启发。云雾物理的覌測工作也已开 始。在实际覌測中，不断改进了自己試制的仪器，对 云滴譜、雨滴譜、云雾的含水量等的覌測問題，也有 了一些体会。

一年来的成績不仅是初步开展了工作，更重要的 是我們的干部队伍逐漸成长起来了。許多以前没有接 触过人工降水和云雾物理的同志, 現在或者已能进行 野外試驗，或者已有条件进行理論的初步研究，或者 可以制出一定水平的一些仪器了。一边在野外工作，一 边学习, 一边㸴究, 这是一种有效的迅速开展工作的 方法。

一年来的人工降水工作，我訩为是方向对头，发 展汛速，工作健康的。

人类主动控制天气，这本来是气象工作者一个极 为重要的斗爭方向。固然就目前的科学技术条件来說, 距离完全控制天气还有一段不小的距离，但是人工影 响云雾則是已經有了相当成就了。大跃进以前，就我 們地球物理研究所来說, 开始时只是积极注意了天气
預报問題，无疑的，这在当前是很重要的，是为国民 經济部門所迫切需要的。但是預报和分析終究是不够 的，还不能适应广大劳动彗众在大跃进中所提出的改 造自然的伟大抱負的要求。而我們对这个問題是理解 不够的，党給我們明确地指出了这一点，使我們迅速 实地地开展了这方面的工作，确定了研究人工降水的 正确方向。

为了实現人工降水,需要进行云雾物理的研究。过 去，我們也不是不想进行这方面的工作，但是一直没 有找到正确的作法，总是希堭先单独地把云雾物理建 立起来，然后再搞人工降水工作，因而两方面的工作 都迟迟没有开始。大跃进中一反过去的想法，先行开 始了人工降水工作，这样不仅带动了云雾物理研究的 开展，而且由于接触到了許多实际問題，从而对云雾 物理的重要內容也有了体会。近一二十年来，云雾物 理发展极快，文献不下二三千篇，如果要用讨去开展 工作的办法，先慢慢看交献，这样不仅拖延了时間,而 且由于不了解其中問題的輕重和相互关系，也难于决 定在这些文献中应該先从何处看起。而今天，云雾物 理工作不仅能够下手了, 财且工作是紧渠結合实际的, 因此工作的进展也是迅速的。

爭取高速度，这对我們这样一个科学落后的国家 說来，无疑是极端重要的。大家知道，現代科学的許 多部門发展很快，如果我們在建立这些学科中爭取不 到高速度，那么将永远不能很好地滿足飞跃前进的社 会主义建設的需要，也永远不会赶上世界先进水平。

人工降水工作一反过去那样关門研究、最后逐步 推广的作法，一开始就是在各地党政机关的領导下,与 广大䁷众一起进行的。去年大跃进以来，各地广大量 众紛紛提出与天争水，向天要水，保証工农业大跃进 的积极愿望，因而人工降水工作一开始就得到了各地 党委的領导和地方气象工作者的积极参加。一年来人 工降水工作的迅速发展, 也标志着科学工作走翌众路 綫的胜利。

一年来的工作不仅是发展快, 而且也是健康的,工 
作正在愈作愈細致，愈作愈踏实。当然，其他新工 作的开始过程一样,一年的工作中也存在一些缺点。由 于工作开展快，技术力量赶不上，因而工作有的不免 粗精些，对降水效果的检查不够細致。但是，这是前 进中的缺点，已經或正在継續克服。

根据过去工作中的体驗，䚯識到以后的人工降水 工作必須坚持結合生产需要的方針，多做試驗，要特 別注意尽量利用自然条件，多搞地形云。这样較有希 㖕得实际效果。但是，人工降水工作，就世界范围 来研，也只是处于幼年时期。由于天气㳡程包括因素 很多, 很复杂, 室气的流动性又很大, 因此, 也应該 估計到人工降水試驗工作的长期性。我国緯度偏南， 水汽旰盛，云中水分可能特別多，对流活动也强烈，地 形复杂，动力与热力的强迫上升都比較强，对人工降 水最有利的地形云在我国特別多等等，这些都是在我 国开展人工降水試驗的有利的自然条件。只要我們坚 持政治掛帥和走丵众路綫的原則，在今后的工作中一 定可以不断取得有意义的进展。

消贫的工作是值得注意的。气象工作者經过实际 覌察，看到雲众对預报冰霓的确是有一定經驗的，北 到临洮，南到鶴庆，翌众有着一些共同的預报經驗，这 不可能是偶然的巧合。至于消要的效果，也决不象一 些“正統”的云雾物理学家所䚿为的那样不可信, 而是 有道理的。今年对土法消隺的覌測証明，問題在于气 策学的水平还不够高, 还没有好好地理解和总結概括 叓众的許多經驗。土法消察是很值得进一步組織力量 深入試驗的，通过試驗很可能把人工降水工作向前推 进一步。当然, 其它消管方法也值得研究。

为了更好地取得数据进行科学分析，在云雾物理
仪器的設計和制造方面需要大大提高。不仅要有合适 的飞机探測仪器, 抹且还要有能进入强烈的对流中部 的云雾物理仪器。这种云里还有着許多重要的秘密等 待我們来揭露。还要对特殊的降水云层, 如特別薄或 降水特别多的云、地形云等进行专門的覌測, 了解它 的特性。这方面的結論都会对人工降水工作有直接的 启发。应該指出,对热带里的云至今研究得还很少, 更 不必說我国完全需要掌握自己的云的特殊性了。

理論工作也是一个重要方面。仪器設計、䓎剂 用量、效果分析、数据解释等，都必須有理論工作的 指导才能进行得好。缺乏理諭的指导，事前既不能做 合适的工作布置，事后也难得出确定的結論，結果会 使很有意义的工作成为可信不可信的东西，这就不能 使人工降水的水平迅速提高。

我們还要更好地学习苏联先进的人工降水和云雾 物理方面的丰富經驗。二十多年来，苏联在人工降水 和云雾物理方面不断地进行着有系統有組織的广泛試 驗和研究，取得了显著的卓越的成就。这是英美等資 本主义国家也不得不承䚯的事实。在开展人工降水工 作中，我敩得必須极积向苏联学习。

回頋一年来波䦩壮闊的人工降水工作，使我們体 会到党的总路䋐的正确和伟大，大跃进运动的正确和 伟大，冲天干劲与科学分析相結合的方針的正确和伟 大。通过反右傾的学习,我們更好地領会了总路紋、大 跃进的精神，我們要千方百計地使人工降水和云雪物 理工作迅速改变面貌。我們相信，在党的正确領导下， 在工作同志的积极努力下，我国人工降水和云雾物理 工作一定会很快地进一步战进。

\section{更 正}

1.本刊 1959 年第 17 期 552 頁右栏交献中应加入“[2]吉村信吉, 1934,陆水学杂志, 4:11一27。”, “[2]、[3]、[4]”应 依次改为“[3]、[4]、[5]”; 同期封三第 9 行中“Chinghai Lake”应为“Kukunor”。

2. 本刊 1959 年第 20 期 698 頁右栏第 30 行“矿朱勘探”应为“找矿勘探”; 699 頁左栏第 8 行应加入“(5)南部連山加

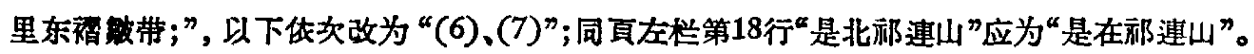

3. 本刊 1959 年第 21 期封二第 11 行 “амортизация”应为“изное”。 